\title{
A Study of the Relationship between China's Fiscal Expenditure Structure and Urban-Rural Income Gap
}

\author{
Li-Ting FANG ${ }^{1, a, b,{ }^{*}}$ \\ ${ }^{1}$ Department of Statistics, School of Economics and Management Fuzhou University, Fuzhou \\ 361005, P.R. of China

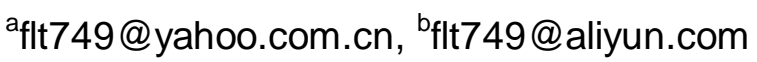 \\ ${ }^{*}$ Corresponding author
}

\begin{abstract}
Keywords: Structure of Fiscal Expenditure; Income Gap between Urban and Rural Residents; Additive Non-parametric Model
\end{abstract}

\begin{abstract}
This paper uses additive non-parametric model to study the linear and nonlinear relation between china's fiscal expenditure structure and urban-rural income gap. The result shows that the structure of fiscal expenditure has a significant linear and nonlinear impact on income gap between urban-rural residents, but different item of fiscal expenditure takes a different impact. Finally, this paper proposed some suggestions to reduce the gap between urban and rural residents.
\end{abstract}

\section{Introduction}

With the development of economic and society, people's material conditions and living standards has also been greatly improved and enhanced in China. However, there are a series of social conflicts in China, such as the widening urban-rural income gap. The expansion of the urban-rural income gap is not conducive to the growth of the long-term economic growth and social harmony and stability. Therefore, how to solve the problem of urban-rural income gap has a great theoretical and practical significance. The reason of the increasingly expanding of China's urban-rural income gap is complex. However, as the primary means of income adjustment and macroeconomic regulation, fiscal expenditure policy has an important impact on Chinese residents' income distribution. Just at this point, we decide to study the question of the structure of financial expenditure and income gap between urban and rural residents.

There are a large number of researches about the issue of financial expenditure and income inequality in domestic and foreign country. Foreign scholars Chu et al (2000) found that, the effect of the tax policies and transfer payment system on narrowing the income gap is not obvious on average. Through empirical analysis $\mathrm{Wu}$ et al (2006) found that different fiscal policy has different effect on the urban-rural income gap. Domestic scholars Lu and Chen (2004) showed that the increasing of the proportion of infrastructure and agriculture expenditure can help narrow the income gap between urban and rural residents, and the increasing of the proportion of science, education, culture and health expenditure will expand the urban-rural income gap. Liu and Wang (2008) found that, the major fiscal expenditure can narrow the income gap between urban and rural residents effectively. Mo and Zhang (2011) showed that the increase in fiscal expenditure would increase social Gini coefficient and the fairness of income distribution would be deteriorated by analyzing the urban-rural dual structure model.

\section{Model Specification and Data Description}

There exist some researches about relationship between the structure of financial expenditure and the urban-rural income gap by using linear regression models. But there is limitation that the linear parametric model cannot describe the non-linear effects among the variables effectively. Therefore, we choose additive non-parametric model to fit the relationship between the structure of fiscal expenditure and income gap between urban-rural residents . 
In order to analyze the effect of fiscal expenditure structure on the urban-rural income gap empirically, We established the following additive non-parametric model:

$$
Y_{i t}=C+x_{i t}^{T} \alpha+D_{i t}^{T} \beta+\sum_{j} g_{j}\left(x_{j i t}\right)+\varepsilon_{i t}
$$

Where $\mathrm{C}$ is the intercept, $\alpha, \beta$ are the coefficient vectors respectively. $\varepsilon_{i t}$ is the residual term. $Y$ refers to the urban-rural income gap index(the Gini coefficient). $x_{j}$ is the proportion of the main fiscal expenditure item in the local financial expenditure and also is the core variable. $D_{k}$ is the control variable. The meaning of each variable can be seen in Table 1. First half of the right-hand side of equation (1) is conventional linear model (parametric regression model);second half are a series of unknown functions with no prior assumption form which can describe the nonlinear effects of the variables on the urban-rural income gap (non-parametric additive model). We selected a sample including all the provinces, municipalities and autonomous regions except Tibet.

Table 1 Variables and their symbols

\begin{tabular}{|c|l|c|l|c|l|}
\hline Symbol & \multicolumn{1}{|c|}{ Variable } & Symbol & \multicolumn{1}{|c|}{ Variable } & Symbol & \multicolumn{1}{|c|}{ Variable } \\
\hline ny & $\begin{array}{l}\text { the proportion of } \\
\text { agricultural } \\
\text { expenditure }\end{array}$ & $\mathrm{kjw}$ & $\begin{array}{l}\text { the proportion of } \\
\text { science, education } \\
\text {,culture and health } \\
\text { expenditure }\end{array}$ & $\mathrm{kf}$ & $\begin{array}{l}\text { the proportion of the } \\
\text { total imports and } \\
\text { exports expenditure in } \\
\text { GDP }\end{array}$ \\
\hline js & $\begin{array}{l}\text { the proportion of } \\
\text { infrastructure } \\
\text { expenditure }\end{array}$ & $\mathrm{sb}$ & $\begin{array}{l}\text { the proportion of } \\
\text { Society security } \\
\text { expenditure }\end{array}$ & $\mathrm{CPI}$ & price index \\
\hline xzg & $\begin{array}{l}\text { the proportion of } \\
\text { administrative } \\
\text { costs }\end{array}$ & city & $\begin{array}{l}\text { non-agricultural } \\
\text { population ratio }\end{array}$ & gro & GDP growth rate \\
\hline
\end{tabular}

The estimation method of the established non-parametric additive model can be summarized in three categories: Back fitting Algorithm proposed by Buja, Hastie and Tibshirani (1989), Marginal Integration Method proposed by Linton and Nielsen(1995) and Local Quasi-Differencing Approach proposed by Christopeit and Hoderlein(2003). Taking into account that Back fitting Algorithm is a ingenious iterative method and its calculation can be simplified, we use Back fitting Algorithm which is the most mainstream approach to estimate in this paper.

There are many variables in this paper and the data of some variables is missing in a given year . Taking into account the availability of relevant data and statistical consistency, we selected the data from the year 1995-2006. Raw data are from "China Statistical Yearbook", "China Population Statistics Yearbook", "China Population and Employment Statistical Yearbook " and "New China Sixty Years Statistical Information Compilation".

\section{Empirical Results Analysis}

Model estimation results can be seen in table 2 (linear results), table 3 and figure 1 (non-linear results). In order to avoid heteroscedasticity, all the variables were taken the logarithm except cpi and gro . 
Table 2 linear results

\begin{tabular}{lrrrr}
\hline Paremeter & Paremeter estimate & Standard error & T value & Pr $>|\mathrm{t}|$ \\
\hline Intercept & -1.92311 & 0.03625 & -53.05 & $<.0001$ \\
city & -0.32922 & 0.05303 & -6.21 & $<.0001$ \\
kf & 0.12853 & 0.02355 & 5.46 & $<.0001$ \\
cpi & 0.01120 & 0.00140 & 8.02 & $<.0001$ \\
gro & -0.00000132 & 0.00266 & -0.00 & 0.9996 \\
js & 0.01929 & 0.00160 & 12.06 & $<.0001$ \\
Xzg & 0.08217 & 0.00479 & 17.16 & $<.0001$ \\
kjw & 0.02146 & 0.00236 & 9.11 & $<.0001$ \\
sb & 0.01253 & 0.00185 & 6.78 & $<.0001$ \\
ny & 0.05241 & 0.00363 & 14.44 & $<.0001$ \\
\hline
\end{tabular}

Table 3 non-linear test results

\begin{tabular}{lccccc}
\hline variable & city & kf & cpi & gro & js \\
\hline Pr $>$ ChiSq & $<.0001$ & 0.0031 & 0.0449 & 0.0710 & 0.0001 \\
\hline variable & xzg & kjw & sb & ny & \\
\hline Pr $>$ ChiSq & $<.0001$ & 0.9466 & $<.0001$ & 0.0060 & \\
\hline
\end{tabular}
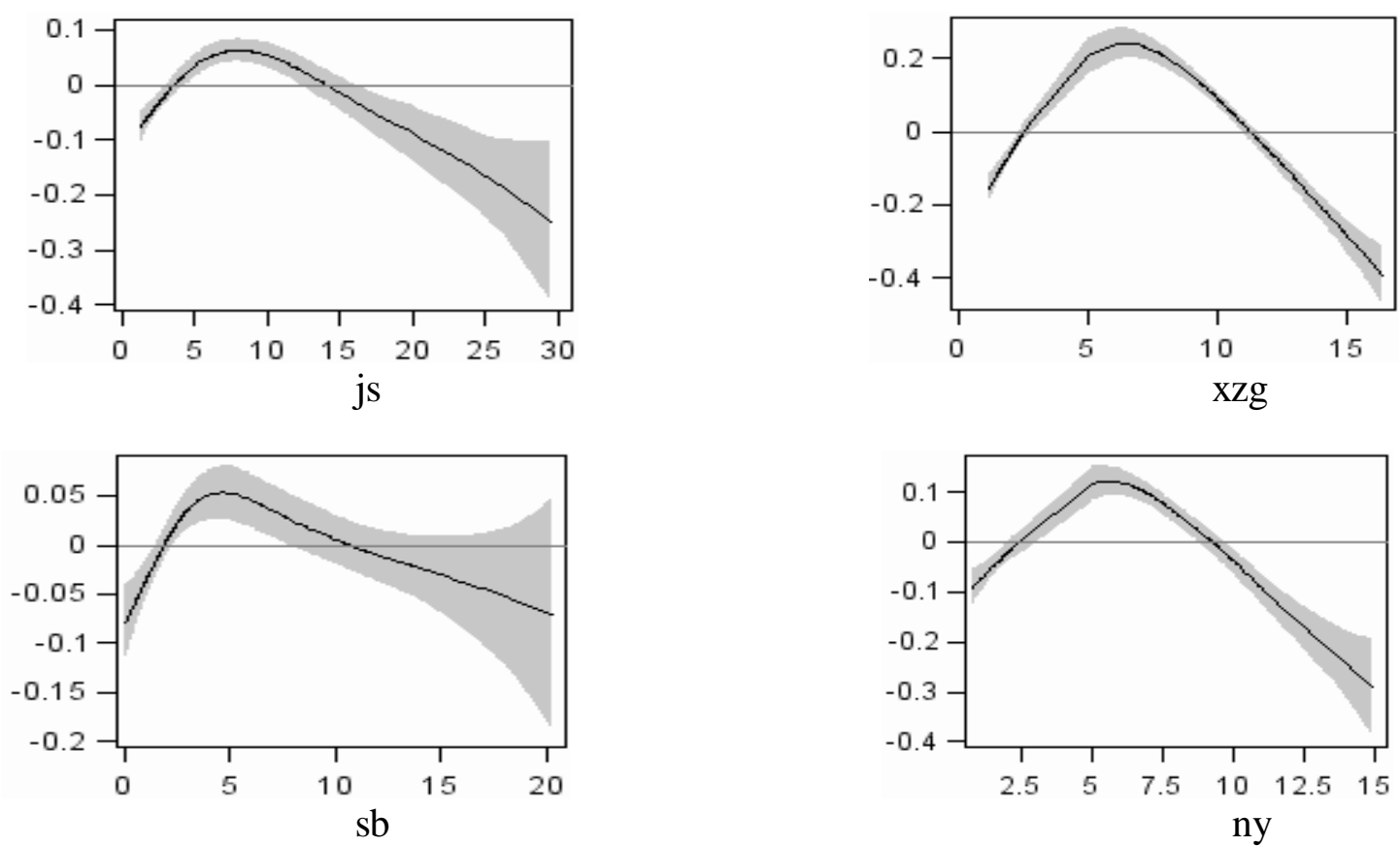

Figure 1 Nonlinear effect of each item of fiscal expenditure

Linear Results. It can be seen from table 1 that urban-rural income gap function is fitted better. The coefficient of five core variables is significantly positive, this shows that the increasing in capital construction expenditure, administrative costs, Society security expenditure, agricultural expenditure and science, education, culture and health expenditure will expand urban-rural income gap. We also can see that the coefficient of openness index(kf) and CPI index is significantly positive and the coefficient of urbanization(city) is significantly negative.

Non-linear results. Table 2 describes the nonlinear test results of each variable. Here, we only consider the core variables with significant nonlinear impact. Shaded areas in the figure indicate $95 \%$ confidence band. Vertical axis represents the impact of the independent variable on the dependent variable and the horizontal axis indicates the values of independent variables.

It can be seen from figure 1 that the impact of infrastructure expenditure, administrative costs, society security expenditure and agricultural expenditure on Gini coefficient shows an "inverted U" shaped 
non-linear trend. This shows that the income gap between urban and rural residents will be expanded firstly, and then it will be narrowed with the increasing of these expenditures.

\section{Conclusion}

This paper uses additive non-parametric model firstly to study the impact of local fiscal expenditure structure on the income gap between urban and rural residents empirically, and then analyzes the linear and nonlinear effects of each item of fiscal expenditure on the income gap between urban and rural residents. According to the empirical results, the income gap between urban and rural residents will be expanded firstly, and then narrowed with the increasing of each item of fiscal expenditure. We believed that is mainly due to the urban bias policies. Therefore, Chinese government should increase the fiscal input to achieve coordinated development of urban and rural areas.

\section{References}

[1] K. Chu, D. Hamid and G. Sanjeev: IMF Working Paper (2000)

[2] X. Wu, M. Jeffrey and G. Amos: Review of Income and Wealth, Vol. 52-2(2006), p. 213-235

[3] A. Buja, T. Hastie and R. Tibshirani: Annals of Statistics, Vol. 17-2(1989), p. 543-555

[4] N. Christopeit and S.Hoderlein: Preprint(2003)

[5] O. B. Linton and J. P. Nielsen: Biometrika, Vol. 82(1995), p. 93-100

[6] M. Lu and Z. Chen: Economic Research Journal (in Chinese), 6(2004), p. 50-58

[7] C. Liu and C. Wang: Public Finance Research (in Chinese), 2(2008), p. 15-18

[8] Y. Mo and Z. Zhang: The Journal of Quantitative \& Technical Economics (in Chinese), 3(2011), p. 79-89 